\begin{tabular}{|c|c|c|}
\hline & Int.J.Curr.Microbiol.App.Sci (2021) 10(12): 133-138 & \\
\hline & $\begin{array}{l}\text { International Journal of Current Microbiology and Applied Sciences } \\
\text { ISSN: 2319-7706 Volume } \mathbf{1 0} \text { Number } \mathbf{1 2} \mathbf{( 2 0 2 1 )} \\
\text { Journal homepage: } \underline{\text { http://www.ijcmas.com }}\end{array}$ & 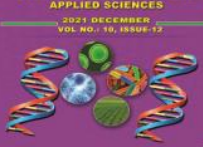 \\
\hline $\begin{array}{l}\text { EXCELLENT } \\
\text { PUBLISHERS }\end{array}$ & & \\
\hline
\end{tabular}

Original Research Article

https://doi.org/10.20546/ijcmas.2021.1012.014

\title{
Genetic Variability Studies for Yield and Related Attributes in Rice Genotypes (Oryza sativa L.)
}

\author{
Monika Singh*, Shweta, Vijay Kumar Yadav, Rajendra Kumar Yadav, \\ Poonam Singh and Anjani Kumar Singh
}

Department of Genetics and Plant Breeding, Chandra Shekhar Azad University of Agriculture
and Technology, Kanpur - 208002, Uttar Pradesh, India

*Corresponding author

\section{Keywords}

Salt stress condition, genotypes, check varieties, pooled, variability,

Stress score

\section{Article Info}

Received:

04 November 2021 Accepted: 30 November 2021 Available Online: 10 December 2021
The experiment on present investigation was conducted for assessment of genetic variability during kharif 2018 and 2019, at Crop Research Farm, Nawabganj and Seed Multiplication Farm Bojha, Chandra Sheker Azad University of Agriculture and Technology, Kanpur (U.P.) India under four environments taking into consideration of high to normal salt stress condition. The experimental materials comprising of 100 genotypes and six standard check varieties (PUSA36, CSR10, CSR36, CSR43, IR64, Usar Dhan 3), grown in Augmented Randomized Block Design with replications of check. Observations were obtained for. Days to $50 \%$ flowering, Days to maturity, Plant height $(\mathrm{cm})$, Stress score at vegetative stage, Panicle bearing tillers/ plant, Panicle length $(\mathrm{cm})$, Spikelets/ panicle, Number of grains/panicle, Spikelet fertility (\%), Biological yield /plant, Grain yield / plant (g), Harvest index (\%), Stress score at reproductive phase,1000- grains weight. Analysis of variance for augmented design in pooled over environment of the environment showed the significant pattern for all fourteen traits. The Analysis of variance revealed the highly significant differences among the genotypes for all the characters under study. The genotypes exhibited a wide range of variability for most of the traits. From the study, it is clear that the traits like Stress score at vegetative stage, stress score at reproductive phase and Grain yield/ plant exhibiting highest values of PCV, GCV. It is highly recommended to select these traits except Spikelet fertility to attain increased yield Days to maturity, 1000-grain weight followed by plant height, Panicle length, Biological yield/plant exhibiting low values of variance hence these traits are ineffective to attain gain by practicing selection. The genotypes IL 773 followed by IL444, IL 105, IL 277, IL 891, IL 125, IL 344, IL 1121 and IL655 produced high grain yield plant-1 and these lines constituted significant group for higher grain yield/plant. The most of the genotypes also showed high to very high mean performance for several other yield components. The superior lines identified for grain yield and other characters may be used as donor parents in hybridization programme under Alkalinity for improving the characters for which they showed high mean performance. 


\section{Introduction}

Rice plays a pivotal role in food security of many countries. It is one of the most extensively cultivated cereal crops in the world, spreading across a wide range of geographies, ecological and climatic regions (Surapaneni et al., 2016). Rice belongs to genus Oryza of Gramineae family. The genus Oryza has 22 wild species $(2 \mathrm{n}=24,48)$ representing 10 genomic types (AA, BB, CC, BBCC, CCDD, EE, FF, GG, HHJJ and HHKK). Oryza sativa is a cultivated diploid species. The Oryza sativa is further divided into three sub-species, namely, Indica, Japonica and Javanica. Two major subspecies, indica and japonica, were polyphyletically derived from the wild species $O$. rufipogon and can be distinguished by hybrid sterility and molecular marker.

Over two billion people in Asia alone derive 80 per cent of their energy needs from rice, which contains 80 percent carbohydrates, 7-8 percent protein, 3 percent fat, and 3 percent fiber (Juliano 1985). India is the largest rice growing country, while China is the largest producer of rice. Although, the average productivity of rice is much lower in India than the average productivity at world level. In India nearly 9.38 million ha area is occupied by salt-affected soils out of which 5.5 million ha are saline soils (including coastal) and 3.88 million ha alkali soils. Land is affected by salt of which Uttar Pradesh share $1.29 \mathrm{~m}$ ha. Successive salinity in the soil has the divesting effect on plant growth reducing crop yields worldwide that leads complete crop failure in worst affected areas.

Variability refers to the presence of differences among the individuals of plant population due to their genetic composition and the environment in which they are raised. Genetic variability is the basis of plant breeding because any crop improvement depends on the amount and direction of genetic association of the traits in the base population. It provides a wide range of genotypes that can be selected to develop new varieties. Development of high yielding varieties requires the existence of genetic variability and genetic variability of agronomic traits is the key component of breeding programs for broadening the gene pool. Selection will be effective when there is a significant amount of variability among the breeding materials.

The available variability can be measured using genotypic and phenotypic coefficient of variation which used to share out genetic and environmental variance. Heritability used to assess the amount of genetic improvement that will be transferred to next generation. However, heritability coupled with genetic advance will be more powerful in predicting genetic gain than heritability alone. In addition, knowledge about the association of traits with themselves and grain yield is also important for direct and indirect selection of traits which contributes to yield. Therefore, further studies aimed at generating and comparing information on above aspects in rice are warranted to facilitate development of high yielding pure line as well as hybrid cultivars.

\section{Materials and Methods}

The experiment was conducted during year 2018 and 2019, at Crop Research Farm, Nawabganj and Seed Multiplication Farm Bojha, Chandra Sheker Azad University of Agriculture and Technology, Kanpur (U.P.) India. experimental material comprised of one hundred genotypes of cultivated rice and six standard check varieties (PUSA36, CSR10, CSR36, CSR43, IR64, Usar Dhan 3) as salt stress sensitive, in Augmented Randomized Block Design with replications of check under four environments taking into consideration of 
soil types (high to normal salt stress condition) and days of sowing. The details of the environments are given below:

\section{Environments}

E-1: Environment I, Year 2018, high stress, pH 9.36, Ec $1.59 \mathrm{dsm}^{-1}$, Seed Multiplication Farm, Bojha,

E-2: Environment II, Year 2018, Normal stress Year 2019, $\mathrm{pH}$ 8.5, Ec0.93dsm ${ }^{-1}$ CRF, Nawabganj,

E-3: Environment III, Year 2019, high stress, $\mathrm{pH}$ 9.48, Ec1.63 $\mathrm{dsm}^{-1}$, Seed Multiplication Farm, Bojha,

E-4: Environment IV, Normal stress Year 2019, pH 8.7, Ec 0.98dsm ${ }^{-1}$ CRF, Nawabganj.

Experimental field was divided into ten blocks of equal size and each block had sixteen plots. Out of sixteen plots in a block, ten plots were used for accommodating the test genotypes which were not replicated while remaining six were allocated to checks i.e. PUSA36, CSR10, CSR36, CSR43, IR64, Usar Dhan 3. The six checks were randomly allocated along with the test genotypes in a block each genotype was grown in seven-row, $01 \mathrm{~m}$ length following row to row and plant to plant spacing of $15 \mathrm{~cm}$ and $15 \mathrm{~cm}$ respectively.

Recommended cultural practices were practiced to raise a good crop. Five plants in all genotype and checks were selected at random from each replication for recording of observations on characters of these genotype were used for recording all the below mentioned characters. The average of observations recorded on these five plants was considered for statistical analysis. Plant morphological characters of each genotype were recorded by selecting single or group of plants depending on all characters at different stages of crop growth. Days to 50\% flowering, Days to maturity, Plant height $(\mathrm{cm})$, Stress score at vegetative stage, Panicle bearing tillers/ plant, Panicle length $(\mathrm{cm})$, Spikelets/ panicle, Number of grains/panicle, Spikelet fertility (\%), Biological yield /plant, Grain yield / plant (g), Harvest index (\%), Stress score at reproductive phase, 1000- grains weight. The analysis of variance for different characters in augmented block design was done according to Federer (1956) and variability for different characters was estimated as suggested by Burton and DeVane (1953).

\section{Results and Discussion}

Analysis of variance for augmented design in pooled over environment of the environment showed the significant pattern for all fourteen traits. The results of ANOVA revealed considerable variation over the traits under study exhibiting a wide range of phenotypic as well as genotypic coefficient of variation. In general, the values of phenotypic coefficient of variance were higher than those of genotypic coefficient of variance. The relative magnitudes of the phenotypic as well as genotypic variances between the traits were compared based on the phenotypic and genotypic coefficient of variation. In present investigation, the estimates of PCV were higher than their corresponding GCV for all the traits studied (Table 2). But most of the traits considered have the small difference between PCV and GCV values specifying less effect of environment in expression of these characters suggesting phenotypic differences may be considered as genotypic difference among the genotypes for selection. These findings were in accordance with the findings of Lal and Chauhan et al., (2011); Singh et al., (2013); Lingaiah et al., (2015); Mishu et al., (2016). 
Table.1 Analysis of variance (pooled) of augmented design for 14 characters in rice genotypes

\begin{tabular}{|c|c|c|c|}
\hline & \multicolumn{3}{|c|}{ Sources of variation } \\
\hline Characters & Blocks & Checks & Error \\
\hline & d.f. (9) & d.f. (5) & d.f. (45) \\
\hline Days to 50\% flowering & $303.99 * * *$ & $970.59 * * *$ & $\mathbf{8 6 . 2 8}$ \\
\hline Days to maturity & $77.42 * * *$ & $127.79 * * *$ & $\mathbf{2 0 . 9 2}$ \\
\hline Plant height (cm) & 227.18 & $1067.157 * * *$ & $\mathbf{1 8 8 . 9 3}$ \\
\hline $\begin{array}{c}\text { Stress score at vegetative } \\
\text { stage }\end{array}$ & $4.51 * * *$ & $34.36 * * *$ & $\mathbf{0 . 7 8}$ \\
\hline $\begin{array}{c}\text { Panicle bearing } \\
\text { tillers/plant }\end{array}$ & 3.22 & $11.70 * * *$ & $\mathbf{1 . 9 9}$ \\
\hline Panicle length & 8.582 & 50.05 & $\mathbf{3 1 0 . 2 6}$ \\
\hline Spikelets /panicle & 382.04 & 2639.51 & $\mathbf{1 8 5 8 . 8 3}$ \\
\hline Number of grains/panicle & 606.78 & 1998.30 & $\mathbf{2 4 1 3 . 5 2}$ \\
\hline $\begin{array}{c}\text { Spikelet fertility } \\
\text { Biological yield/plant }\end{array}$ & 125.55 & 145.09 & $\mathbf{1 2 3 . 1 8}$ \\
\hline $\begin{array}{c}\text { Grain yield/ plant } \\
\text { Harvest index (\%) } \\
\text { Stress score at } \\
\text { reproductive phase }\end{array}$ & $39.61 * * *$ & $2610.42 * * *$ & $\mathbf{3 . 0 5}$ \\
\hline $\begin{array}{c}\text { 1000-grain weight } \\
\text { *Significant at 5\% probability level **Significant at } 1 \% \text { probability level }\end{array}$ & 8.37 & $109.94 * * *$ & $\mathbf{7 . 5 7}$ \\
\hline
\end{tabular}

*Significant at $5 \%$ probability level, **Significant at $1 \%$ probability level

Table.2 Range, mean and coefficient of variation for 14 characters of rice genotypes

\begin{tabular}{|c|c|c|c|c|}
\hline Characters & Range & Mean & \multicolumn{2}{|c|}{ Coefficient of variation } \\
\hline & $($ min-max $)$ & & PCV $(\%)$ & GCV (\%) \\
\hline Days to 50\% flowering & $77.85-111.69$ & 97.11 & 15.55 & $\mathbf{1 2 . 2 6}$ \\
\hline Days to maturity & $115.51-115.51$ & 127.12 & 7.08 & $\mathbf{6 . 0 9}$ \\
\hline Plant height (cm) & $81.60-112.78$ & 98.69 & 9.77 & $\mathbf{9 . 2 3}$ \\
\hline $\begin{array}{c}\text { Stress score at vegetative } \\
\text { stage }\end{array}$ & $0.86-4.72$ & 2.31 & 98.26 & $\mathbf{9 0 . 4 4}$ \\
\hline $\begin{array}{c}\text { Panicle bearing } \\
\text { tillers/plant }\end{array}$ & $5.12-9.40$ & 7.45 & 28.13 & $\mathbf{2 0 . 7 8}$ \\
\hline Panicle length & $18.61-26.42$ & 22.60 & 13.43 & $\mathbf{8 . 5 8}$ \\
\hline Spikelets /panicle & $95.24-167.60$ & 142.97 & 19.12 & $\mathbf{1 1 . 6 7}$ \\
\hline Number of grains/panicle & $67.87-140.14$ & 111.23 & 31.53 & $\mathbf{1 0 . 5 1}$ \\
\hline Spikelet fertility & $57.70-92.26$ & 75.86 & 16.11 & $\mathbf{6 . 7 4}$ \\
\hline Biological yield/plant & $29.46-43.58$ & 35.53 & 14.74 & $\mathbf{1 3 . 9 0}$ \\
\hline Grain yield/ plant & $5.81-13.89$ & 10.50 & 39.33 & $\mathbf{2 9 . 3 3}$ \\
\hline Harvest index (\%) & $18.27-39.45$ & 29.34 & 33.15 & $\mathbf{2 2 . 6 5}$ \\
\hline $\begin{array}{c}\text { Stress score at } \\
\text { reproductive phase }\end{array}$ & $1.29-5.30$ & 3.40 & 66.69 & $\mathbf{4 9 . 0 5}$ \\
\hline 1000-grain weight & $\mathbf{1 6 . 6 2 - 2 3 . 5 1}$ & $\mathbf{2 1 . 3 7}$ & $\mathbf{1 0 . 4 8}$ & $\mathbf{6 . 9 3}$ \\
\hline
\end{tabular}


The traits sterile Stress score at vegetative stage followed by Stress score at reproductive phase and Grain yield/ plant recorded highest values of PCV and GCV. Whereas the traits such as Days to maturity, 1000-grain weight followed by plant height, Panicle length, Biological yield/plant, had low estimates of PCV and GCV showing that selection for these traits will be relatively less effective. However, in case of Spikelet fertility the difference was relatively higher indicating relatively greater effect of environment on this trait. The similar case has been reported earlier by Mustafa and Elsheikh (2007), Singh et al., (2008), Raut et al., (2009), Idris et al., (2012). The characters exhibited moderate phenotypic coefficient of variation (PCV) and genotypic coefficient of variation (GCV) values, are likely to allow reasonable scope of improvement through selection in respective environment owing to their moderate genetic variability (Garg et al., 2011, Tiwari et al., 2011).

Heritability analyses estimate the relative contributions of differences in genetic and non-genetic factors to the total phenotypic variance in a population. It is an important concept in quantitative genetics, particularly in selective breeding. The heritability in broad sense $(\mathrm{H} 2)$ estimate varied from $17.50 \%$ to $90.54 \%$, respectively for Spikelet fertility and Panicle length. Mostly all the characters studies had high heritability except the numbers of Spikelet fertility. This result indicates that these characters could be easily improved by selection.

Genetic advance (GA) under selection refers to the improvement of characters in genotypic value for the new population compared with the base population under one cycle of selection at a given selection intensity (Wolie et al., 2013). The high value of GA was recorded with 1000-grain weight (9.44) and the low (74.43) Stress score at reproductive phase. Estimates of GA for yield/plant was $4.69 \mathrm{~g} / \mathrm{plant}$ indicating that whenever we select the best, $5 \%$ high yielding genotypes as parents, average grain yield/plant of progenies could be improved by $4.69 \mathrm{~g} / \mathrm{plant}$.

The Analysis of variance revealed the highly significant differences among the genotypes for all the characters under study. The genotypes exhibited a wide range of variability for most of the traits. From the study, it is clear that the traits like Stress score at vegetative stage, Stress score at reproductive phase and Grain yield/ plant exhibiting highest values of PCV, GCV. It is highly recommended to select these traits except Spikelet fertility to attain increased yield Days to maturity, 1000-grain weight followed by plant height, Panicle length, Biological yield/plant exhibiting low values of variance hence these traits are ineffective to attain gain by practicing selection. The genotypes IL 773 followed by IL444, IL 105, IL 277, IL 891, IL 125, IL 344, IL 1121 and IL655 produced high grain yield/plant and these lines constituted significant group for higher grain yield/plant.

The most of the genotypes also showed high to very high mean performance for several other yield components. The superior lines identified for grain yield and other characters may be used as donor parents in hybridization programme under Alkalinity for improving the characters for which they showed high mean performance.

\section{References}

Garg P, Pandey D P and Singh D. 2011. Genetic variability for yield and quality traits in rice (Oryza sativa L.). Research on Crops 12(1): 182-184.

Idris A E, Justin F J, Dagash Y M I and Abuali A I. 2012. Genetic variability and inter relationship between yield 
and yield components in some rice genotypes. American Journal of Experimental Agriculture 2(2): 233239.

Juliano B O. 1985. Rice chemistry and technology, (2nd Edition). American Association of Cereal Chemists, St Paul, MN, USA. pp 774.

Khush G S and Virk P S. 2000. Rice breeding achievements and future strategies. Crop Improvement 27(2): 115144.

Lal, M. and Chauhan, D. K. 2011. Studies of genetic variability, heritability and genetic advance in relation to yield traits in rice. Agricultural Science Digest, 31(3): 12-19

Lingaiah, N. 2015. Genetic variability, heritability and genetic advance in rice (Oryza sativa L.). Asian Journal of environmental Sciences, 10(1): 110112.

Mishu, F. M., Rahman, W., Azad, M. A. K., Biswas, B. K., Talukder, A. I., Kayers, O., Islam, R. and Alam, R. 2016. Study on genetic variability and character association of aromatic rice (Oryza sativa L.) cultivar. International Journal of Plant and Soil Science, 9(1): 1-8.

Mustafa M A and Elsheikh M A Y. 2007.
Variability, correlation and path coefficient analysis for yield and its components in rice. African Crop Science Journal 15(4): 183-189.

Raut K R, Harer P N and Yadav P S. 2009. Genetic variability and character association in rice (Oryza sativa L.). Journal of Maharashtra Agriculture University 34(2): 174-178.

Singh, A. K., Nandan, R. and Singh, P. K. 2013. Genetic variability and association analysis in rice germplasm under rainfed conditions. Crops Research, 47(1-3): 7-11.

Singh L, Ram D and Singh B. 2008. Genetic variability and character association in paddy. Progressive Research 3(2): 209-210.

Tiwari D K, Pandey P, Tripathi S, Giri S P and Dwivedi J L. 2011. Studies on genetic variability for yield components in rice (Oryza sativa L.). $A A B$ Bioflux 3(1): 76- 81.

Wolie A, Dessalegn T, Belete K. 2013. Heritability, variance components and genetic advance of some yield and yield related traits in Ethiopian collections of finger millet (Eleusine coracana (L.) Gaertn.) genotypes. Afr. J. Biotechnol. 12(36):5529-5534.

\section{How to cite this article:}

Monika Singh, Shweta, Vijay Kumar Yadav, Rajendra Kumar Yadav, Poonam Singh and Anjani Kumar Singh. 2021. Genetic Variability Studies for Yield and Related Attributes in Rice Genotypes (Oryza sativa L.). Int.J.Curr.Microbiol.App.Sci. 10(12): 133-138. doi: https://doi.org/10.20546/ijcmas.2021.1012.014 